\title{
THIERRY LAGET, Proust, Prix Goncourt. Une émeute
}

\section{littéraire}

\section{Ludovico Monaci}

\section{OpenEdition}

\section{Journals}

\section{Edizione digitale}

URL: https://journals.openedition.org/studifrancesi/32153

DOI: 10.4000/studifrancesi.32153

ISSN: 2421-5856

\section{Editore}

Rosenberg \& Sellier

\section{Edizione cartacea}

Data di pubblicazione: 1 août 2020

Paginazione: 434

ISSN: 0039-2944

\section{Notizia bibliografica digitale}

Ludovico Monaci, «thierry Laget, Proust, Prix Goncourt. Une émeute littéraire», Studi Francesi [Online], 191 (LXIV | II) | 2020, online dal 01 septembre 2020, consultato il 18 septembre 2021. URL: http:// journals.openedition.org/studifrancesi/32153 ; DOI: https://doi.org/10.4000/studifrancesi.32153

Questo documento è stato generato automaticamente il 18 septembre 2021.

\section{(a) $\odot \Theta$}

Studi Francesi è distribuita con Licenza Creative Commons Attribuzione - Non commerciale - Non opere derivate 4.0 Internazionale. 


\title{
THIERRY LAGET, Proust, Prix Goncourt. Une émeute littéraire
}

\author{
Ludovico Monaci
}

\section{NOTIZIA}

THIERRY LAGET, Proust, Prix Goncourt. Une émeute littéraire, Paris, Hermann, 2019, «Blanche», $262 \mathrm{pp}$.

1 Per tutti gli studiosi e gli amanti della Recherche, il 10 dicembre 1919 rappresenta la data in cui Marcel Proust viene incoronato vincitore del prix Goncourt, grazie a À l'ombre des jeunes filles en fleurs. Thierry Laget celebra il centenario dell'evento attraversando tutte le tappe che hanno portato alla consacrazione letteraria dell'autore. Le voci di corridoio sui favoriti, le indiscrezioni della stampa, nonché le maldicenze e i pettegolezzi delle personalità coinvolte si avvicendano nelle sedici vivaci sezioni argomentative che rendono conto dell'«émeute littéraire» legata all'assegnazione del prestigioso premio.

2 «La truffe et le salsif» (pp. 9-16) e «Plus inconnu que tant de débutants» (pp. 17-28) tracciano le coordinate storiche del Goncourt, dalla sua istituzione fino all'anteguerra, quando Du côté de chez Swann ottenne, fresco di pubblicazione nel 1913, la preferenza del solo Rosny aîné. Un'indagine sulla ricezione dell'autore da parte della stampa («Le cas Marcel Proust», pp. 45-50) è preceduta dalla rassegna biobibliografica dei dieci componenti dell'Académie Goncourt del 1919 («Des hommes qui savent ce qu'est le roman», pp. 29-44). La sezione «L'honneur périlleux de se battre» (pp. 51-58) punta invece i riflettori sull'avversario principale di Proust: Roland Dorgelès, autore de Les croix de bois, opera che era già un successo letterario ancor prima che venisse pubblicato il secondo volume della Recherche («Tirages comparés», pp. 247-248).

3 «À qui le prix Goncourt?» (pp. 59-82) e «Un homme qui dort» (pp. 83-96) riassumono gli schieramenti della giuria - Daudet, Geoffroy, Céard, Bourges e Rosny aîné per Proust; Ajalbert, Hennique, Descaves per Dorgelès - e i dibattiti che hanno avuto luogo al 
ristorante Drouant per stabilire il vincitore. Al terzo scrutinio, il fratello minore di Rosny si assocerà ai sostenitori di Proust: Léon Daudet potrà recarsi in rue Hamelin 44 per consegnare al suo grande amico la lettera del verdetto. Dorgelès rimedierà (seppur soltanto in minima parte) alla sconfitta con il premio Femina-Vie heureuse («Des douces mains de femmes», pp. 107-116). Dal canto suo, Proust - il cui profilo è ricostruito minuziosamente in «L'homme à qui il n'est rien arrivé» (pp. 117-132)-dovrà fronteggiare numerosi attacchi da parte dei giornalisti e degli addetti ai lavori («Et il reprendra Fantômas», pp. 97-106; «Beaucoup de bruit pour une omelette», pp. 133-142). Tutto questo non gli impedirà comunque di collezionare «Mille lettres de félicitations» (pp. 143-152).

4 La sezione «Ce radotage des Danaïdes» (pp. 153-168) prende le mosse da un articolo pubblicato il 23 dicembre 1919 sulla rivista "Comœdia": il già nominato Rosny aîné, da sempre strenuo sostenitore di Proust, fa luce su una serie di calunnie relative alla "sponsorizzazione" di Daudet, all'età e alla ricchezza del vincitore che, troppo reazionario per gli spiriti di sinistra e troppo tiepido (oltre che dreyfusista) per quelli di destra, non trova un gran numero di adepti («Empoisonnés d'Action française», pp. 169-184). «Roland Dorgelès, prix Goncourt» (pp. 185-198) rivela invece la frode pubblicitaria che Albin Michel pagò a caro prezzo nel promuovere Les croix de bois su "Le Figaro": l'editore fu infatti costretto a versare 2000 franchi di multa a Gallimard. Il clamore mediatico dell'evento fu l'occasione di rilanciare Du côté de chez Swann, oltre che per sancire il successo dell'intera opera negli anni a venire («De l'autre côté du Temps», pp. 199-210).

5 La ricchezza di riferimenti giornalistici, storici e letterari, la presenza di aneddoti coloriti, lo stile mordace e i toni spesso ironici (pur nella serietà e nella sostenutezza della trattazione) fanno del lavoro di Laget un'avvincente cronaca delle vicissitudini del prix Goncourt 1919. 